\title{
REVIEW
}

\section{Hemostatic abnormalities in endocrine and metabolic disorders}

\author{
Massimo Franchini ${ }^{1}$, Giuseppe Lippi ${ }^{2}$, Franco Manzato ${ }^{3}$, Pier Paolo Vescovi ${ }^{4}$ and Giovanni Targher ${ }^{5}$ \\ ${ }^{1}$ Servizio di Immuno-ematologia e Medicina Trasfusionale and ${ }^{2}$ U.O. Diagnostica Ematochimica, Dipartimento di Patologia e Medicina di Laboratorio, \\ Azienda Ospedaliero-Universitaria, 43100 Parma, Italy, ${ }^{3}$ Laboratorio di Analisi Chimico-Cliniche and ${ }^{4}$ Divisione di Medicina, Ospedale 'Carlo Poma', \\ 46100 Mantova, Italy and ${ }^{5}$ Sezione di Endocrinologia, Dipartimento di Scienze Biomediche e Chirurgiche, Università di Verona, 37126 Verona, Italy \\ (Correspondence should be addressed to M Franchini; Email: mfranchini@ao.prit)
}

\begin{abstract}
The hemostatic balance is a complex system where the delicate equilibrium is regulated by several factors, including hormones. This review summarizes current knowledge of the effects of most frequent endocrine and metabolic diseases (such as hypothyroidism, hyperthyroidism, Cushing's syndrome, GH-related pituitary dysfunctions, pituitary prolactin-producing adenomas, polycystic ovary syndrome, primary hyperparathyroidism, and metabolic syndrome) on coagulation and fibrinolysis. Overt hypothyroidism appears to be associated with a bleeding tendency, whereas all other endocrine diseases appear to be associated with a thrombotic tendency. Globally, the disorders of coagulation and fibrinolysis usually range from mild to moderate, and, rarely, to severe laboratory abnormalities (for example, bleeding diathesis in overt hypothyroidism mainly due to an acquired von Willebrand's disease type 1). Further larger and high-quality studies are needed to provide more definitive information on the effects of endocrine disorders on coagulation and fibrinolysis.
\end{abstract}

European Journal of Endocrinology 162 439-451

\section{Introduction}

Endocrine disorders may have a significant influence on the hemostatic balance. Several abnormal coagulation test results have been described in patients with abnormal hormone levels (1). As schematically shown in Fig. 1, two pathways of blood coagulation have been recognized: the so-called extrinsic or tissue factor (TF) pathway and the so-called intrinsic or contact activation pathway (2). These two pathways of activation of the coagulation cascade converge to form a 'common' pathway, which leads to the generation of the pivotal coagulation enzyme thrombin. Thrombin not only catalyzes the conversion of fibrinogen to fibrin, but also exerts a key role in amplifying the cascade by feedback activation of coagulation factors at several sites (the so-called 'thrombin burst') (2). Several physiological antithrombotic mechanisms act in concert to prevent clotting under normal circumstances. Optimal activity of each of the anticoagulant systems depends on the integrity of vascular endothelium. Several of these physiological antithrombotic mechanisms, including antithrombin, the protein $\mathrm{C} /$ protein S/thrombomodulin system, and TF pathway inhibitor (TFPI), act at different sites in the coagulation cascade to dampen fibrin accumulation (2). Fibrin that forms despite these anticoagulant defenses is then degraded by the fibrinolytic system. Plasminogen is the inactive zymogen form of plasmin, which represents the major protease enzyme of the plasma fibrinolytic system, acting to digest fibrin to fibrin degradation products (2). The major physiological plasminogen activators that convert plasminogen to plasmin are tissue-type plasminogen activator ( $\mathrm{t}-\mathrm{PA}$ ) and urokinase-type plasminogen activator (u-PA), although the former is prevailing under physiological circumstances (2). Physiological regulation of plasma fibrinolysis occurs primarily at two levels: i) plasminogen activator inhibitors (PAIs), principally PAI-1, inhibit the physiological plasminogen activators, t-PA and u-PA, in plasma, and ii) alpha 2-antiplasmin inhibits plasmin (2). Further regulation of fibrinolysis occurs by a unique feedback mechanism of thrombin generation via the thrombin-activatable fibrinolysis inhibitor (TAFI) that inhibits fibrinolysis through the removal of carboxy-terminal lysine residues on fibrin monomers, eliminating plasminogen and t-PA-binding sites that normally serve to augment t-PA-mediated conversion of plasminogen to plasmin (2). Table 1 summarizes the main antithrombotic and prothrombotic factors in plasma.

This review critically appraises studies examining the effects of the most common endocrine and metabolic disorders - such as hypothyroidism, hyperthyroidism, Cushing's syndrome, GH-related pituitary dysfunction, pituitary prolactin (PRL)-producing adenomas, polycystic ovary syndrome (PCOS), primary hyperparathyroidism (PHPT), and metabolic syndrome - on coagulation and fibrinolysis. 


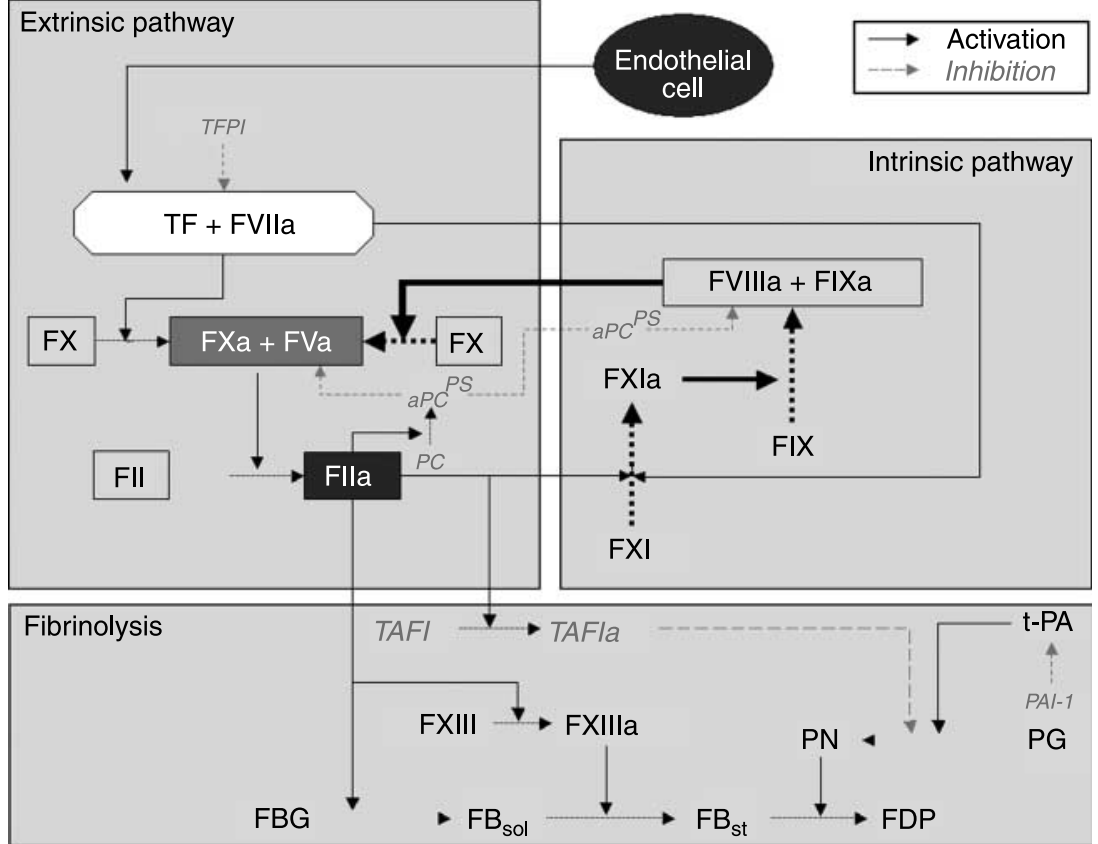

Figure 1 Schematic representation of the coagulation and fibrinolytic systems. F, factor; FBG, fibrinogen; FDP, fibrin/ fibrinogen degradation products; FB sol, soluble fibrin; FB st, stabilized fibrin; PAI-1, plasminogen activator inhibitor-1; PC, protein C; PS, protein S; PG, plasminogen $\mathrm{PN}$, plasmin; TAFI, thrombin-activatable fibrinolysis inhibitor; TF, tissue factor; TFPI, tissue factor pathway inhibitor; t-PA, tissueplasminogen activator.

\section{Thyroid disorders}

The strong relationship between thyroid hormones and the coagulation system has been appreciated since the beginning of the past century (3). Several biological mechanisms were proposed to explain this intriguing association, including effects of thyroid hormones on synthesis of coagulation factors as well as thyroid-related autoimmune processes, involving the hemostatic system (4-6).

As reported in more detail below, the disorders of coagulation and fibrinolysis in patients affected by overt hyperthyroidism or hypothyroidism usually range from mild to moderate, and, rarely, to potentially severe laboratory abnormalities (e.g. bleeding diathesis in overt hypothyroidism mainly due to an acquired von Willebrand's disease (aVWD) type 1), are rapidly reversible after pharmacologic treatment of the hormonal dysfunction, and are usually of limited consequence in clinical practice. Although future clinical trials on larger series of patients are undoubtedly required to better clarify the hemostatic abnormalities in patients with thyroid dysfunctions, a number of small casecontrol studies have suggested that the influence of thyroid dysfunction on coagulation and fibrinolysis mainly depends on the type of thyroid disorder. In general, patients with clinically overt hypothyroidism appear to have an increased risk of bleeding, whereas those with overt hyperthyroidism are more likely to be prone to thrombosis. At present, very little information is available on hemostatic abnormalities in patients with subclinical hypothyroidism or hyperthyroidism.

\section{Hypothyroidism}

A number of small case-control studies have shown various abnormalities of coagulation and fibrinolysis in patients with overt hypothyroidism (7-10). aVWD is the most relevant coagulation disorder clinically observed in overt hypothyroidism (11-21), and it is mainly characterized by decreased factor VIII activity (FVIII:C), von Willebrand factor antigen (VWF:Ag), and ristocetin cofactor (VWF:RCo) levels. The presenting symptoms

Table 1 Summary of main antithrombotic and prothrombotic factors in plasma.

\begin{tabular}{ll}
\hline Anticoagulant & Procoagulant \\
\hline $\begin{array}{l}\text { Antithrombin } \\
\text { Protein C/protein S/ } \\
\text { thrombomodulin system } \\
\begin{array}{l}\text { Tissue factor pathway } \\
\text { inhibitor (TFPI) }\end{array}\end{array}$ & $\begin{array}{l}\text { Tissue factor (TF) } \\
\text { Tissue factor-bearing } \\
\text { microparticles } \\
\text { Clotting factors } \\
\text { von Willebrand factor (VWF) }\end{array}$ \\
\hline Profibrinolytic & Antifibrinolytic \\
\hline $\begin{array}{l}\text { Tissue-type plasminogen } \\
\text { activator (t-PA) }\end{array}$ & $\begin{array}{l}\text { Plasminogen activator } \\
\text { inhibitor-1 (PAI-1) }\end{array}$ \\
$\begin{array}{l}\text { Urokinase-type plasminogen } \\
\text { activator (u-PA) }\end{array}$ & $\begin{array}{l}\text { Alpha 2-antiplasmin } \\
\text { Thrombin-fibrinolysis } \\
\text { activatable inhibitor (TAFI) }\end{array}$ \\
\hline Platelet inhibitory & Platelet activating \\
\hline $\begin{array}{l}\text { Prostacyclin (PGI2) } \\
\text { Nitric oxide (NO) } \\
\text { Carbon monoxide (CO) }\end{array}$ & $\begin{array}{l}\text { Platelet-activating factor (PAF) } \\
\text { Endothelin-1 }\end{array}$ \\
\hline & Thromboxane A2 (TXA2) \\
\hline
\end{tabular}


are easy bruising, epistaxis, or mucosal bleeding. However, the diagnosis of this coagulopathy is difficult since it is usually not detected by routine laboratory tests, and often hypothyroidism may have an insidious onset with subtle clinical signs and symptoms. Therefore, the correct diagnosis is frequently not established until bleeding tendency is revealed by major hemorrhages following trauma or surgery. We studied 1342 consecutive patients with various thyroid diseases undergoing thyroid surgery (20); a pre-operative coagulation screening, including prothrombin time (PT), activated partial thromboplastin time (APTT), and platelet function (using the PFA-100 analyzer), identified 39 patients ( $\sim 3 \%$ of the whole sample) with coagulation abnormalities, 35 of which had aVWD (20). On the other hand, aVWD could also represent the first sign of an undiagnosed hypothyroidism, and thereby individuals presenting with low plasma VWF levels should also be screened for their thyroid hormonal status (21). The pathogenesis of hypothyroidism-associated aVWD is still unclear. A decrease in VWF protein synthesis or a decreased response to adrenergic stimulation (enhancing the VWF release from endothelial cells) due to hormone deficiency is the most plausible mechanisms involved, as also supported by the finding of a reversal of the hypothyroidism-associated aVWD following thyroid hormone replacement $(5,22)$.

In addition to decreased plasma VWF levels, patients with overt hypothyroidism may have, in some cases, a megakaryocytopoiesis that is severely inhibited by bone marrow myxedema (7).

Qualitative platelet abnormalities have also been reported in patients with hypothyroidism (23-25). Palareti et al. (26) studied 21 patients with acquired hypothyroidism after thyroidectomy, and observed an impaired platelet reactivity not only to ristocetin but also to collagen and adrenalin, which was rapidly normalized after thyroid hormone replacement therapy. Myrup et al. (23) reported a significant prolongation of bleeding time, an impaired agglutination response to ristocetin, and an increased platelet aggregation in response to ADP in 19 hypothyroid patients as compared to euthyroid controls. Notably, these hemostatic abnormalities normalized after L-thyroxine $\left(\mathrm{L}-\mathrm{T}_{4}\right)$ therapy, suggesting that the prolonged primary hemostasis seen in overt hypothyroidism may be a direct consequence of the hormonal dysfunction (23).

As regards the coagulation-fibrinolytic abnormalities in overt hypothyroidism, Egeberg (27) and Simone et al. (28) also documented a significant reduction in coagulation factors VIII, IX, and XI activities in hypothyroid patients. Further small case-control studies (29-31), although not all $(32,33)$, confirmed these findings and also reported lower levels of plasma coagulation factors VII, X, and XII in hypothyroid patients. Auto-antibodies against factor VIII (aHA, acquired hemophilia A) may also occasionally develop in hypothyroidism caused by chronic autoimmune thyroiditis (34). Chadarevian et al. (35) studied the fibrinolytic system in hypothyroid patients and documented a different plasma fibrinolytic pattern according to the severity of hypothyroidism: an increased plasma fibrinolytic activity (i.e. lower levels of alpha 2-antiplasmin, t-PA, and PAI-1 and higher D-dimer) was observed in overt hypothyroidism, whereas a hypofibrinolytic tendency (i.e. higher levels of alpha 2-antiplasmin, t-PA, and PAI-1 and lower D-dimer) was found in subclinical hypothyroidism. Other small case-control studies confirmed the presence of hypofibrinolysis in patients with subclinical hypothyroidism $(8,36,37)$, further supporting the possibility that this condition might be associated with increased risk of cardiovascular disease (38).

\section{Hyperthyroidism}

Platelet abnormalities have been observed in patients with overt primary hyperthyroidism (39-41). Indeed, a number of small case-control studies documented an association between hyperthyroidism and autoimmune thrombocytopenic purpura (AITP) (42-47). Cordiano et al. found that $\sim 80 \%$ of patients with hyperthyroidism and thrombocytopenia had platelet autoantibodies (48). Conversely, Marshall et al. reported that 6 of 42 patients (14\% of total) with diagnosed AITP developed hyperthyroidism during the follow-up of the study (43).

However, several other mild to moderate abnormalities of the coagulation-fibrinolytic systems have been reported in patients with overt hyperthyroidism, predisposing these patients to a hypercoagulable state rather than to a bleeding tendency (5). For example, it is known that there is a biological link between antiphospholipid antibodies and Graves' disease (49-53). Moreover, Homoncik et al. found increased plasma VWF levels and enhanced platelet function (as measured with PFA-100 analyzer) in patients with hyperthyroidism compared with euthyroid controls (54). Loeliger et al. found that overt hyperthyroidism may increase the turnover rates of coagulation factors II, VII, and X (55). Rogers et al. (29) reported that 21 of 22 untreated hyperthyroid patients had increased plasma FVIII:C, VWF:Ag, and VWF:Rco levels, which normalized after treatment with methimazole. The same authors documented a significant increase in plasma VWF:RCo and factor VIII coagulant activity and related antigen in 14 healthy volunteers after receiving a short-term $\mathrm{L}_{-} \mathrm{T}_{4}$ therapy (56). We have recently shown that in a sample of 1329 unselected adult outpatients, those with hyperthyroidism had shortened APTT and higher plasma fibrinogen levels when compared with euthyroid patients, whereas no significant differences were observed between euthyroid patients and those with hypothyroidism, thus confirming that overt hyperthyroidism is associated with mild to moderate hypercoagulability (57). Finally, increased plasma factor X activity levels, another marker of a hypercoagulable state, were 
recently described by Erem et al. in patients with subclinical hyperthyroidism (58). The same authors studied the blood coagulation and fibrinolysis in 41 patients with overt hyperthyroidism (41); they found that patients with hyperthyroidism had increased levels of plasma fibrinogen, factor IX, VWF, antithrombin, and PAI-1 and decreased levels of t-PA compared with euthyroid controls, confirming a reduced plasma fibrinolytic activity. Other small case-control studies showed an impaired fibrinolytic activity in hyperthyroid patients $(59,60)$.

\section{Cushing's syndrome}

Several small reports have reported an increased incidence of both venous and arterial thrombotic events in patients with active Cushing's syndrome (61-68), underlining the existence of a prothrombotic state in this condition. To date, a number of studies have experimentally explored the effects of acute hypercortisolism on the coagulation and fibrinolytic systems (1). In vitro studies have shown a lower fibrinolytic activity induced by corticosteroids, mainly due to a stimulated synthesis/secretion of PAI-1 (69-71). Increased levels of thrombin-antithrombin complex (caused by elevated procoagulant factors and decreased antithrombin) have been documented by Jacoby et al. in a canine model (72). The activation of the coagulation system and a reduction of plasma fibrinolytic activity have also been confirmed in small clinical studies conducted in patients with chronic hypercortisolism (73-76). Several investigators have shown higher levels of plasma VWF, factor VIII, factor IX, factor XI, and factor XII in patients with active Cushing's syndrome than in healthy controls (75-78). Conversely, a recent case-control study did not find any significant difference in plasma PAI-1, t-PA, and VWF levels between patients with Cushing's syndrome and control subjects (79).

In a retrospective observational study, Boscaro et al. (80) assessed the incidence of postoperative venous thromboembolic events in 307 patients with active Cushing's syndrome, including 75 patients (group 1) not receiving anticoagulants and undergoing routine hemostatic function testing (i.e. PT and APTT), and 232 patients (group 2) receiving anticoagulation therapy with heparin or warfarin and undergoing a thorough investigation as to hemostatic parameters. Compared with control subjects, those with active Cushing's syndrome showed various abnormalities of plasma hemostatic parameters (increased levels of VWF:Ag and VWF:RCo, FVIII:C, PAI-1, and fibrinogen). An inverse, significant correlation was also observed between APTT and 24-h urinary free cortisol excretion. Interestingly, during the follow-up, 15 patients $(20 \%)$ from group 1 and 14 patients (6\%) from group 2 developed venous thromboembolic complications (80). Eight of these patients in group 1 and one in group 2 died. Overall, survival analysis demonstrated a significantly lower mortality and morbidity for venous thromboembolism in patients in group 2, who were treated with anticoagulants in the perioperative period until cure of the endocrine disease (80). To further explore the acute effects of glucocorticoids on the coagulation system, Brotman et al. performed a small controlled clinical study (81). They randomized 24 healthy men to receive either dexamethasone $3 \mathrm{mg}$ twice daily or placebo for 5 days, and then controlled several plasma hemostatic factors (clotting factors VII, VIII, and XI, VWF, D-dimer, PAI-1, and fibrinogen) before and after drug intervention; dexamethasone significantly increased plasma factor VII, factor VIII, factor XI, and fibrinogen levels (81).

Recently, Van Zaane et al. (82) performed a systematic review on the chronic effects of active Cushing's syndrome on coagulation and fibrinolysis. The authors confirmed that there is an increased risk of unprovoked and post-operative venous thromboembolism in patients with Cushing's syndrome (82). Glucocorticoid-induced hypercoagulability as well as surgery and obesity, conditions that are commonplace in patients with Cushing's syndrome, almost certainly contributes to this prothrombotic tendency. In this review, it was also reported that no univocal statistical differences in plasma hemostatic markers can be found between patients with active Cushing's syndrome and those in remission. Likewise, no clear difference was observed for subclinical Cushing's syndrome due to adrenal adenomas (82). In the absence of prospective randomized clinical trials, there is currently a general agreement that thromboprophylaxis should be routinely used in patients with active Cushing's syndrome undergoing transsphenoidal or adrenal surgery. However, future large prospective trials are needed to evaluate the type, intensity, and duration of thromboprophylaxis.

\section{GH-related pituitary dysfunctions}

There are some data in the current scientific literature based on small case-control and intervention studies suggesting the presence of a prothrombotic state in patients with GH-related pituitary dysfunctions - as reported in detail below. However, further information from larger case-control and intervention studies is needed to better clarify the effects of GH-related pituitary dysfunctions on the coagulation-fibrinolytic system.

\section{Acromegaly}

Acromegaly is associated with an increased risk of cardiovascular morbidity and mortality (83). Indeed, GH hypersecretion may adversely affect carbohydrate and lipid metabolism, thus contributing to the high thrombotic risk profile of such patients. Some small 
case-control studies suggested the presence of a prothrombotic tendency in acromegalic patients that might partially contribute to the development of cardiovascular complications (1). For example, in a small case-control study, Wildbrett et al. (84) reported higher levels of plasma PAI-1 and t-PA in 23 patients with active acromegaly than in healthy controls. Moreover, a positive, significant association was observed between plasma insulin-like growth factor 1 (IGF1), GH, and PAI-1 levels among these patients (84). Recently, Erem et al. (6) reported higher plasma fibrinogen, antithrombin, and PAI-1 levels, and lower protein S activity and TFPI levels in 22 patients with active acromegaly than those in 22 age-matched healthy controls. Serum GH levels were inversely correlated to plasma TFPI levels, and there was also a negative correlation between IGF1 and PAI-1 (6). A significant increase in plasma fibrinogen and t-PA levels was also reported by Sartorio et al. in ten acromegalic patients (85). Interestingly, LandinWilhelmsen et al. showed significantly higher plasma fibrinogen concentrations, but similar values of PAI-1 activity, in 20 patients with active acromegaly compared with 20 age-, sex-, and body weight-matched control subjects (86). Plasma fibrinogen was positively associated with IGF1 levels, and decreased following pharmacological treatment of acromegaly (86). A beneficial effect of a short-term treatment with somatostatin analogs on plasma fibrinogen and PAI-1 was also reported by Delaroudis et al. in 18 acromegalic patients (87).

\section{GH deficiency}

A very small number of case-control studies suggested the presence of a mild to moderate prothrombotic state in adult patients with GH deficiency, which could partly contribute to the increased risk for arterial and venous thrombosis seen in hypopituitarism (88-91). Increased circulating levels of VWF, thrombomodulin, and some endothelial adhesion molecules (such as intercellular adhesion molecule-1 and E-selectin) were observed by Elhadd et al. in 52 GH-deficient adults (91). Sartorio et al. reported increased plasma levels of PAI-1, fibrinogen, and thrombin-antithrombin complex in 24 patients with adult-onset GH deficiency (85). Similarly, Johansson et al. showed a significant increase in plasma fibrinogen and PAI-1 activity levels in 20 $\mathrm{GH}$-deficient adults, and demonstrated reversal of these hemostatic abnormalities after 2 years of recombinant human GH replacement therapy $(92$, 93). Almost identical results were observed in a small intervention study by Kvasnicka et al. (94), who confirmed a favorable effect of a 1-year GH replacement therapy on plasma fibrinogen, PAI-1, intercellular adhesion molecule-1, and E-selectin levels in GH-deficient adults (95). In contrast, no significant changes in plasma fibrinolytic markers were observed by Gomez et al. in ten GH-deficient adults following short-term $\mathrm{GH}$ replacement therapy (96), whereas significant increases in PT and APTT values, but not in plasma fibrinogen, were reported by Miljic et al. in $21 \mathrm{GH}$-deficient adults after 12 months of GH replacement treatment (97).

\section{Prolactinomas}

Although several conditions (pregnancy, estrogen, and antipsychotic therapy) increase plasma PRL levels, pituitary PRL-producing adenomas represent the most common endogenous cause of hyperprolactinemia. Currently, there is very little information on the effects of this hormone on the coagulation and fibrinolytic systems. However, Wallaschofski et al. have experimentally shown that hyperprolactinemia is a potent platelet co-stimulator due to the potentiation of ADPinduced platelet aggregation $(98,99)$. The same group of investigators also assessed the potential association between hyperprolactinemia and venous thromboembolism. Plasma PRL levels were significantly higher in 98 patients with unprovoked venous thromboembolism without congenital risk factors than those in healthy controls (100). Finally, according to other two small studies $(101,102)$, hyperprolactinemia could be implicated in enhanced platelet reactivity seen in patients with ischemic stroke or acute coronary syndromes. Nevertheless, further larger case-control and intervention studies are needed that directly investigate the hemostatic and fibrinolytic disorders in patients with prolactinomas.

\section{Polycystic ovary syndrome}

PCOS is a common endocrine disorder, affecting up to $10 \%$ of women of reproductive age, associated with multiple co-morbidities such as type 2 diabetes, dyslipidemia, hypertension, and metabolic syndrome, all of which predispose women with PCOS to early atherosclerosis (103). PCOS women also have a higher prevalence of subclinical atherosclerosis as reflected in dysregulation of endothelial function, increased carotid intima-media thickness and presence of coronary artery calcification $(104,105)$. The largest retrospective survey of PCOS women in the United Kingdom could not confirm an increased all-cause and cardiovascular mortality (106). However, one explanation might be that the number of deaths was quite small, and longer follow-up might be advisable to show the adverse effect of PCOS on mortality. At present, there are quantitatively limited data on abnormalities in the coagulation-fibrinolytic system in PCOS women. Yildiz et al. found that 58 nonobese, nondiabetic PCOS women had a significantly lower global fibrinolytic capacity than age- and weight-matched controls $(n=23)$, which was inversely associated with serum testosterone levels 
(107). In contrast, no significant differences were found in PT, APTT, antithrombin, D-dimer, plasminogen, fibrinogen, or factor II, V, VII, and X activities between the two groups (107). Kelley et al. measured plasma fibrinogen, factor VII, VWF, t-PA antigen, and D-dimer concentrations in 17 young PCOS women and 15 ageand weight-matched controls (108). Of these plasma hemostatic markers, only t-PA concentration was significantly elevated in PCOS women relative to controls (108). A reduced plasma fibrinolytic activity - as measured by PAI-1, TAFI, or euglobulin clot lysis time - in PCOS women was also confirmed in some, but not all, small case-control studies (109-112).

\section{Primary hyperparathyroidism}

Patients with PHPT have a higher prevalence of hypertension, glucose intolerance, altered vascular tone, presence of coronary artery calcification, and are at increased risk for future cardiovascular events; this risk appears to decrease with time after parathyroidectomy (113-115).

Abnormalities in coagulation and fibrinolysis pathways have been detected in PHPT, although the evidence is still conflicting and mostly supported by a small number of case-control studies. Erem et al. reported that 24 patients with symptomatic PHPT had significantly higher plasma levels of t-PA and PAI-1, and lower TFPI levels than those in 20 age-, sex- and body weight-matched controls (116). Moreover, serum parathyroid hormone (PTH) levels were positively associated with plasma PAI-1 levels in PHPT patients (116). In a previous article, the same authors found increased platelet count, higher activities of factor VII and IX, and increased levels of D-dimer in 23 PHPT patients compared with healthy controls, whereas no significant differences were found in plasma fibrinogen, VWF, factor $\mathrm{V}$, factor IX, antithrombin, protein $\mathrm{C}$, protein $\mathrm{S}$, t-PA, and PAI-1 between the two groups (117). ChertokShacham et al. reported a positive, graded, relationship between plasma PTH and PAI-1 levels in 35 patients with symptomatic PHPT without clinically manifest cardiovascular disease (118). However, further larger case-control and intervention studies are needed that directly investigate the hemostatic and fibrinolytic disorders in PHPT patients.

\section{Metabolic syndrome}

The metabolic syndrome represents a public health concern because its prevalence is steadily increasing worldwide - affecting up to one-third of the general adult population in various countries - and it is strongly associated with an increased risk of future cardiovascular events $(119,120)$. The metabolic syndrome is a cluster of inter-related metabolic abnormalities, which includes abdominal overweight/obesity, glucose intolerance (i.e. impaired fasting glycemia, impaired glucose tolerance or type 2 diabetes), insulin resistance, atherogenic dyslipidemia (i.e. high triglycerides and low high-density lipoprotein (HDL)-cholesterol) and hypertension, all established risk factors for cardiovascular disease (119).

As recently reviewed by several investigators including our group (120-125), the metabolic syndrome is frequently associated with a hypercoagulable condition, in that the coagulation system is switched toward a prothrombotic state, involving increased plasmatic coagulation, reduced fibrinolysis, decreased endothelial thromboresistance, and predominantly platelet hyperactivity. All of these abnormalities in the coagulation and fibrinolytic systems may contribute to the development of cardiovascular complications in patients with the metabolic syndrome.

\section{Circulatory endothelium dysfunction}

Endothelial dysfunction is defined as an alteration of vascular relaxation induced by reduction of endothelium-derived relaxing factors, mainly nitric oxide (NO), causing a relative predominance of the vasoconstrictive stimuli and a prothrombotic tendency in the vasculature (126-128). Insulin resistance, a pathogenic factor of the metabolic syndrome, is thought to be a key determinant of this process, by suppressing the synthesis and release of both NO and prostacyclin (PGI2) by endothelium, and by increasing the synthesis and bioavailability of endothelin-1 (126-128). Impaired endothelial NO synthesis plays a central role in the pathophysiology of vascular disease. In addition to its vasodilatory activity, NO inhibits platelet aggregation and adhesiveness, reduces vascular permeability, and inhibits vascular smooth muscle cell proliferation (126-128). Glucotoxicity, lipotoxicity, and chronic inflammation play a pathogenetic role in the development of circulatory endothelial dysfunction - through mechanisms possibly mediated by the activation of nuclear factor K- $\beta$ and other transcription factors - and may further aggravate insulin resistance, thereby promoting the development of other metabolic abnormalities $(128,129)$. The adipose tissue, especially visceral adipose tissue, is an endocrine organ that secretes several pro-inflammatory and pro-atherogenic mediators, including free fatty acids, leptin, resistin, visfatin, tumor necrosis factor (TNF)- $\alpha$, interleukin (IL)-6 and PAI-1 and (decreased) adiponectin (119, 123, $125,130)$. Particularly, in the presence of abdominal obesity, the 'dysfunctional' adipocyte, as also specifically reflected by lower adiponectin and higher IL-6 and TNF- $\alpha$ levels, may exert its adverse systemic effects contributing to endothelial dysfunction, chronic inflammation, insulin resistance, and accelerated atherogenesis (125-130). TNF- $\alpha$ inhibits lipoprotein-lipase action and increases oxidative stress and acute phaseproteins synthesis $(125,128-131)$. Similarly, IL-6 
inhibits insulin signaling/action and activates endothelial cells, thus modulating the systemic inflammatory response; it also participates in the systemic immune response and the increased monocyte expression of TF $(125,128-131)$.

\section{Platelet hyperactivity}

In general, platelets from patients with the metabolic syndrome - especially those with glucose intolerance and abdominal obesity - show increased adhesiveness and hyperaggregability, both spontaneous and in response to stimulating agents $(120,123,124$, 132-134). The possible causes for this activation are multifold: altered exposure and/or abundance of glycoprotein receptors for agonists and adhesive proteins on the platelet surface, increased binding of fibrinogen, decreased membrane fluidity, altered platelet metabolism, and changes in intra-platelet signaling pathways $(120,123,124,132-134)$. The altered biophysical state of platelet membrane components in the metabolic syndrome may be one of the major determinants of platelet hypersensitivity and hyperfunction, and may contribute to impairments in various metabolic pathways, like intensified calcium mobilization and accentuated thromboxane synthesis and release (132-134). Simultaneously, the presence of endothelial dysfunction and atherogenic dyslipidemia, mainly hypertriglyceridemia, may trigger platelet aggregation, thus further increasing the risk of thrombotic events $(120,123,124,132,133)$. A disorder of triglyceride metabolism is a key feature in the metabolic syndrome, and there is now ample evidence supporting a strong association between hypertriglyceridemia and hypercoagulability (120-125, 135). In particular, the concentrations of very-low density lipoprotein (VLDL) and remnant lipoproteins are often increased in the metabolic syndrome, and they can trigger platelet activation and activate the coagulation pathway, supporting the assembly of the prothrombinase complex (120-125, 135). VLDL can also up-regulate PAI-1 gene expression, thus increasing the PAI-1 concentration and activity in plasma - a process that is strongly associated with increased platelet aggregation and clot formation (120-125, 136). Finally, it has also been shown that the amount of platelet microparticles, small membrane vesicles that support the coagulation by exposure of anionic phospholipids and TF, is closely associated with the increasing number of the components of the metabolic syndrome (137).

\section{Hypercoagulability and hypofibrinolysis}

Several epidemiological and experimental studies have shown that patients with the metabolic syndrome have higher plasma concentrations of fibrinogen, VWF, factor VIII, and factor VII than those without the syndrome (119-125). Moreover, many large cross-sectional studies conducted in different populations have consistently demonstrated that the fibrinolytic parameters PAI-1 and t-PA antigen (which represents t-PA/PAI-1 complexes) are strongly correlated to the components of the metabolic syndrome (especially abdominal obesity, insulin resistance, and hypertriglyceridemia), and that the improvement of insulin resistance may improve the concentration of the fibrinolytic parameters (119-125).

Currently, there is growing evidence that nonalcoholic fatty liver disease (NAFLD), which is now regarded as the hepatic manifestation of the metabolic syndrome $(138,139)$, is strongly associated with a systemic pro-inflammatory/procoagulant state, independently of shared cardiometabolic risk factors. As recently reviewed in detail by our group (140), a number of case-control studies using liver biopsies for diagnosing NAFLD have shown that circulating levels of several proinflammatory (e.g. C-reactive protein, IL-6, IL-8, and TNF- $\alpha$ ) and prothrombotic (e.g. PAI-1, fibrinogen, VWF, and intercellular adhesion molecule1) factors are highest in patients with nonalcoholic steatohepatitis (NASH), intermediate in those with simple steatosis and lowest in nonsteatotic healthy controls, independently of underlying metabolic abnormalities. Notably, some of these studies have reported a strong, graded, relationship between intrahepatic mRNA expression of C-reactive protein, IL-6, or PAI-1 and the histological severity of NASH (140). Recently, we have shown that NASH patients are more insulin resistant and have higher plasma levels of C-reactive protein, fibrinogen, and PAI-1 activity, and lower plasma adiponectin concentrations than overweight, nonsteatotic controls with comparable values of visceral adiposity, thus suggesting that NASH predicts a prothrombotic/procoagulant risk profile in a manner that is partly independent from the contribution of visceral adiposity (141). This finding was further supported by the strong, graded relationships of these plasma inflammatory/hemostatic markers with the histological severity of NASH, independently of visceral adiposity, insulin resistance, plasma triglycerides, and smoking (141). Overall, therefore, the evidence from this and other studies suggests that NASH is not simply a marker of the prothrombotic state in the metabolic syndrome but is directly involved in its pathogenesis, possibly through the systemic release of proinflammatory and procoagulant factors from the steatotic/ inflamed liver (138-140).

Although the available data are still controversial and less conclusive, patients with the metabolic syndrome also exhibit higher plasma levels of TAFI, TF, factor XIII, and endothelial adhesion molecules (e.g. intercellular adhesion molecule-1, P-selectin, and E-selectin) than those without the syndrome (142-145). Moreover, increased endothelial cell microparticles (EMP) release, platelet and leukocyte hyperactivation, increased binding of both EMPs and platelets to leukocytes are also shown in patients with the metabolic syndrome 
Table 2 Summary of main abnormalities of the coagulation and fibrinolytic systems observed in patients with various endocrine and metabolic diseases.

\begin{tabular}{ll}
\hline Endocrine disease(s) & Coagulation-fibrinolytic abnormality \\
\hline $\begin{array}{l}\text { Thyroid dysfunctions } \\
\text { Overt hypothyroidism }\end{array}$ & aVWD, $\downarrow$ coagulation factor levels, aHA, $\uparrow$ fibrinolysis $(\downarrow$ fibrinolysis in subclinical hypothyroidism) \\
Overt hyperthyroidism & AITP, APS, $\uparrow$ VWF levels, $\uparrow$ coagulation factor levels, $\downarrow$ fibrinolysis \\
Cushing's syndrome & $\uparrow$ VWF levels, $\uparrow$ coagulation factor levels, $\downarrow$ fibrinolysis \\
GH-related pituitary dysfunctions & \\
Acromegaly & $\uparrow$ Fibrinogen, $\downarrow$ fibrinolysis \\
GH deficiency & $\uparrow$ Fibrinogen, $\downarrow$ fibrinolysis, endothelial dysfunction \\
Prolactinoma & $\uparrow$ Platelet aggregation \\
Metabolic syndrome & Endothelial dysfunction, $\uparrow$ platelet aggregation, $\uparrow$ VWF levels, $\uparrow$ coagulation factor levels, $\downarrow$ fibrinolysis \\
Polycystic ovary syndrome & $\downarrow$ Fibrinolysis \\
Primary hyperparathyroidism & $\downarrow$ Fibrinolysis \\
\hline
\end{tabular}

aVWD, acquired von Willebrand disease; aHA, acquired hemophilia A; AITP, autoimmune thrombocytopenic purpura; APS, anti-phospholipid syndrome; VWF, von Willebrand factor.

(133, 146). Conversely, plasma levels of anticoagulant protein $\mathrm{C}$, protein $\mathrm{S}$, and antithrombin appear to be decreased in these patients (122-124). In addition, plasma TFPI levels are also shown to be reduced in the metabolic syndrome, and correlate significantly with plasma lipid parameters and obesity $(122-124,147)$.

\section{Conclusions}

There is growing evidence that several abnormalities of the coagulation and fibrinolytic systems can be observed in patients affected by hyperthyroidism, hypothyroidism, GH-related pituitary dysfunctions, pituitary PRL-producing adenomas, Cushing's syndrome, PCOS, PHPT, and metabolic syndrome.

As schematically summarized in Table 2 , clinically overt hypothyroidism appears to be associated with a bleeding tendency, whereas all other endocrine and metabolic disorders appear to be associated with a thrombotic tendency. From a clinical standpoint, it is important to note that these coagulation-fibrinolytic disorders usually range from mild to moderate, and, rarely, to severe laboratory abnormalities. In addition, as they are rapidly reversible after pharmacologic treatment of the hormonal dysfunction, they would appear to be usually of limited importance in clinical practice, providing the underlying disorder is recognized quickly and treated appropriately. On the other hand, the prompt recognition of potentially severe disorders of blood coagulation - for example, bleeding diathesis in some cases of overt hypothyroidism mainly due to an aVWD type 1 - is mandatory for the correct management of these patients. However, it should also be noted that, except for the metabolic syndrome, the number of case-control and intervention studies performed in patients with the above-mentioned endocrine diseases is quantitatively limited, and the sample size of most of these studies is very small. Moreover, the selection of the control group is not always appropriate, and the strength of the few medium-quality studies is tempered by the limited number of coagulation tests performed. Thus, future larger clinical and intervention studies are required to provide more definitive information on the clinical relevance and the effects of the pharmacologic treatment of the hormonal dysfunction on the abnormalities of coagulation and fibrinolysis in these endocrine disorders. At present, there is a general agreement that a high risk of venous thromboembolism is present in patients with active Cushing's syndrome, and that thromboprophylaxis with low-molecular-weight heparin should be (routinely) considered in patients with this disorder undergoing surgery (82). Although the available data are controversial and more extensive studies are necessary, prophylactic anticoagulation might be also recommended in older patients with hyperthyroidism and atrial fibrillation in the presence of other heart disease, hypertension, or other important risk factors for embolization (148). On the contrary, in younger patients with hyperthyroidism and new-onset atrial fibrillation who do not have other heart disease or other risk factors for embolization, the risk of anticoagulant therapy probably outweighs the benefits. Aspirin provides an alternative for lowering risk for embolic events in young people and can be used safely (148). Although low-dose aspirin prophylaxis is frequently recommended also to patients with the metabolic syndrome $(119,123,124)$, there are no specific studies of the use of aspirin or other anti-platelet agents for the primary prevention of cardiovascular disease in individuals with the metabolic syndrome. Long-term use of aspirin therapy has been advocated in the secondary prevention of cardiovascular disease (149), and some important scientific associations have strongly recommended low-dose aspirin in high-risk patients with the metabolic syndrome, especially in 
those with established atherosclerotic cardiovascular disease or type 2 diabetes (150). Until more data are available, however, the prophylactic use of low-dose aspirin in the primary prevention of cardiovascular disease in nondiabetic patients with the metabolic syndrome as well as in those with endocrine diseases included in this review is an attractive therapeutic option to lower cardiovascular events, but it should remain as an 'individual clinical judgment'.

\section{Declaration of interest}

The authors declare that there is no conflict of interest that could be perceived as prejudicing the impartiality of the research reported.

\section{Funding}

This research did not receive any specific grant from any funding agency in the public, commercial, or not-for-profit sector.

\section{Author contribution statement}

M Franchini, G Lippi, and G Targher wrote the manuscript; F Manzato and P P Vescovi revised and approved the final version of the manuscript.

\section{References}

1 Squizzato A, Gerdes VE, Ageno W \& Büller HR. The coagulation system in endocrine disorders: a narrative review. Internal and Emergency Medicine 20072 76-83.

2 Furie B \& Furie BC. Mechanisms of thrombus formation. New England Journal of Medicine 2008359 938-949.

3 Squizzato A, Romualdi E, Büller HR \& Gerdes VE. Thyroid dysfunction and effects on coagulation and fibrinolysis: a systematic review. Journal of Clinical Endocrinology and Metabolism 200792 2415-2420.

4 Franchini M. Hemostasis and thyroid diseases revisited. Journal of Endocrinological Investigation 200427 886-892.

5 Franchini M, Montagnana M, Manzato F \& Vescovi PP. Thyroid dysfunction and hemostasis: an issue still unresolved. Seminars in Thrombosis and Hemostasis $200935288-294$.

6 Erem C. Coagulation and fibrinolysis in thyroid dysfunction. Endocrine 200936 110-118.

7 Ford HC \& Carter JM. Haemostasis in hypothyroidism. Postgraduate Medical Journal 199066 280-284.

8 Erem C, Kavgaci H, Ersöz H, Hacihasanoglu A, Ukinç K, Karti SS, Deger O \& Telatari M. Blood coagulation and fibrinolytic activity in hypothyroidism. International Journal of Clinical Practice 2003 $\mathbf{5 7} 78-81$

9 Hofbauer LC \& Heufelder AE. Coagulation disorders in thyroid diseases. European Journal of Endocrinology 1997136 1-7.

10 Marongiu F, Cauli C \& Mariotti S. Thyroid, hemostasis and thrombosis. Journal of Endocrinological Investigation 200427 1065-1071.

11 Dalton RG, Dewar MS, Savidge GF, Kernoff PB, Matthews KB, Greaves M \& Preston FE. Hypothyroidism as a cause of acquired von Willebrand's disease. Lancet 19871 1007-1009.

12 Blesing NE, Hambley $\mathrm{H}$ \& McDonald GA. Acquired von Willebrand's disease and hypothyroidism: report of a case presenting with menorrhagia. Postgraduate Medical Journal $199066474-476$.

13 Thornton JG, Parapia LA \& Minford AMB. Hypothyroidism and von Willebrand's disease. Lancet 19871 1314-1315.
14 Nitu-Whalley IC \& Lee CA. Acquired von Willebrand syndrome - report of 10 cases and review of the literature. Haemophilia $19995318-326$.

15 Michiels JJ, Schroyens W, Berneman Z \& van der Planken M. Acquired von Willebrand syndrome type 1 in hypothyroidism: reversal after treatment with thyroxine. Clinical and Applied Thrombosis/Hemostasis 20017 113-115.

16 Attivissimo LA, Lichtman SM \& Klein I. Acquired von Willebrand's syndrome causing a hemorrhagic diathesis in a patient with hypothyroidism. Thyroid 19955 399-401.

17 Aylesworth C, Smallridge RC, Rick ME \& Alving BM. Acquired von Willebrand's disease: a rare manifestation of postpartum thyroiditis. American Journal of Hematology $1995 \mathbf{5 0} 217-219$.

18 Tjan-Heijnen VC, Harthoorn-Lasthuizen EJ, Kurstjens RM \& Koolen MI. A patient with postpartum primary hypothyroidism and acquired von Willebrand's disease. Netherlands Journal of Medicine 199444 91-94.

19 Franchini M, de Gironcoli M, Lippi G, Manzato F, Brazzarola P, Bottura D, Aprili G \& Gandini G. Efficacy of desmopressin as surgical prophylaxis in patients with acquired von Willebrand disease undergoing thyroid surgery. Haemophilia 20028 $142-144$.

20 Franchini M, Zugni C, Veneri D, Gandini G, Lippi G, Manzato F \& Brazzarola P. High prevalence of acquired von Willebrand's syndrome in patients with thyroid diseases undergoing thyroid surgery. Haematologica 200489 1341-1346.

21 Franchini M, Veneri D \& Lippi G. Analysis of thyroid hormone status in 131 consecutive individuals with low von Willebrand factor levels. Thrombosis and Haemostasis 200593 392-393.

22 Bruggers CS, McElligott K \& Rallison ML. Acquired von Willebrand disease in twins with autoimmune hypothyroidism: response to desmopressin and L-thyroxine therapy. Journal of Pediatrics 1994125 911-913.

23 Myrup B, Bregengård C \& Faber J. Primary haemostasis and thyroid disease. Journal of Internal Medicine 1995238 59-63.

24 Zeigler ZR, Hasiba U, Lewis JH, Vagnucci AH, West VA \& Bezek EA. Hemostatic defects in response to aspirin challenge in hypothyroidism. American Journal of Hematology 198617 209-215.

25 Edson JR, Fecher DR \& Doe RP. Low platelet adhesiveness and other abnormalities in hypothyroidism. Annals of Internal Medicine 197582 342-346.

26 Palareti G, Biagi G, Legnani C, Bianchi D, Serra D, Savini R \& Coccheri S. Association of reduced factor VIII with impaired platelet reactivity to adrenalin and collagen after total thyroidectomy. Thrombosis and Haemostasis 198962 1053-1056.

27 Egeberg BO. Influence of thyroid function on the blood clotting system. Scandinavian Journal of Clinical and Laboratory Investigation $1963151-7$.

28 Simone JV, Abildgaard CF \& Schulman I. Blood coagulation in thyroid dysfunction. New England Journal of Medicine 1965273 $1057-1061$.

29 Rogers JS, Shane SR \& Jencks FS. Factor VIII activity and thyroid function. Annals of Internal Medicine 198297 713-716.

30 Nordoy A, Vikmo H \& Berntsen H. Haemostatic and lipid abnormalities in hypothyroidism. Scandinavian Journal of Haematology $197616154-160$.

31 Gullu S, Sav H \& Kamel N. Effects of levothyroxine treatment on biochemical and hemostasis parameters in patients with hypothyroidism. European Journal of Endocrinology 2005152 355-361.

32 Chadarevian R, Bruckert E, Ankri A, Beucler I, Giral P \& Turpin G. Relationship between thyroid hormones and plasma D-dimer levels. Thrombosis and Haemostasis 199879 99-103.

33 Müller B, Tsakiris DA, Roth CB, Guglielmetti M, Staub JJ \& Marbet GA. Haemostatic profile in hypothyroidism as potential risk for vascular or thrombotic disease. European Journal of Clinical Investigation 200131 131-137.

34 Meiklejohn DJ \& Watson HG. Acquired haemophilia in association with organ-specific autoimmune disease. Haemophilia $20017523-525$. 
35 Chadarevian R, Bruckert E, Leenhardt L, Giral P, Ankri A \& Turpin G. Components of the fibrinolytic system are differently altered in moderate and severe hypothyroidism. Journal of Clinical Endocrinology and Metabolism 200186 732-737.

36 Cantürk Z, Cetinarslan B, Tarkun I, Cantürk NZ, Ozden M \& Duman C. Hemostatic system as a risk factor for cardiovascular disease in women with subclinical hypothyroidism. Thyroid 2003 13 971-977.

37 Özcan MA, Cömlekçi A, Demrkan F, Yüksel F, Sari I, Demir T, Ozsan GH, Orük G, Yeşil S \& Undar B. Plasma levels of free tissue factor pathway inhibitor in patients with various thyroid disorders. Thrombosis Research 2003110 243-247.

38 Ochs N, Auer R, Bauer DC, Nanchen D, Gussekloo J, Cornuz J \& Rodondi N. Meta-analysis: subclinical thyroid dysfunction and the risk for coronary heart disease and mortality. Annals of Internal Medicine $2008 \mathbf{1 4 8} 832-845$.

39 Farid NR, Griffiths BL, Collins JR, Marshall WH \& Ingram DW. Blood coagulation and fibrinolysis in thyroid disease. Thrombosis and Haemostasis 197635 415-422.

40 Marongiu F, Conti M, Murtas ML, Mameli G, Sorano GG \& Martino E. What causes the increase in platelet mean volume in thyroid pathological conditions? Thrombosis and Haemostasis 199063 323-324.

41 Erem C, Ersöz H, Karti SS, Ukinç K, Hacihasanoglu A, Değer O \& Telatar M. Blood coagulation and fibrinolysis hyperthyroidism. Journal of Endocrinological Investigation 200225 345-350.

42 Hymes K, Blum M, Lackner H \& Karpatkin S. Easy bruising, thrombocytopenia, and elevated platelet immunoglobulin $\mathrm{G}$ in Graves' disease and Hashimoto's thyroiditis. Annals of Internal Medicine 198194 27-30.

43 Marshall JS, Weisberger AS \& Levy RP. Coexistent idiopathic thrombocytopenic purpura and hyperthyroidism. Annals of Internal Medicine 196767 411-414.

44 Adrouny A, Sandler R \& Carmel R. Variable presentation of thrombocytopenia in Graves' disease. Archives of Internal Medicine 1982142 1460-1464.

45 Pinals RS, Tomar RH, Haas DC \& Farah F. Graves' disease, myasthenia gravis and purpura. Annals of Internal Medicine 1977 87250.

46 Yamaguchi K, Ookubo Y, Matsuda H, Suzaki K, Fujushima H \& Uzwa H. Idiopathic thrombocytopenic purpura subsequent to Graves' disease and insulin-dependent diabetes mellitus. Diabetes Research and Clinical Practice 19873 233-237.

47 Hofbauer LC, Spitzweg C, Schmauss S \& Heufelder AE. Graves disease associated with autoimmune thrombocytopenic purpura. Archives of Internal Medicine 1997157 1033-1036.

48 Cordiano I, Betterle C, Spadaccino CA, Soini B, Girolami A \& Fabris F. Autoimmune thrombocytopenia (AITP) and thyroid autoimmune disease (TAD): overlapping syndromes? Clinical and Experimental Immunology 1998113 373-378.

49 Franchini M, Lippi G, Manzato F \& Vescovi PP. Thyroid-associated autoimmune coagulation disorders. Journal of Thrombosis and Thrombolysis 201029 87-91.

50 Marongiu F, Conti M, Murtas ML, Sorano GG, Mameli G, Salis G, Mathieu A \& Martino E. Anti-cardiolipin antibodies in Grave's disease: relationship with thrombin activity in vivo. Thrombosis Research 199164 745-749.

51 Paggi A, Caccavo D, Ferri GM, Di Prima MA, Amorosa A, Vaccaro F, Bonomo L \& Afeltra A. Anticardiolipin antibodies in autoimmune thyroid disease. Clinical Endocrinology $1994 \mathbf{4 0}$ 329-333.

52 Hofbauer LC, Spitzweg C \& Heufelder AE. Graves' disease associated with the primary antiphospholipid syndrome. Journal of Rheumatology 199623 1435-1437.

53 Takahashi A, Tamura A \& Ishikawa O. Antiphospholipid antibody syndrome complicated by Graves' disease. Journal of Dermatology 200229 776-780.

54 Homoncik M, Gessl A, Ferlitsch A, Jilma B \& Vierhapper H. Altered platelet plug formation in hyperthyroidism and hypothyroidism. Journal of Clinical Endocrinology and Metabolism 200792 3006-3012.
55 Loeliger EA \& Esch B. The biological disappearance rate of prothrombin, factors VII, IX and X from plasma in hypothyroidism, hyperthyroidism and during fever. Thrombosis et Diathesis Haemorrhagica 196310 267-277.

56 Rogers JS \& Shane SR. Factor VIII activity in normal volunteers receiving oral thyroid hormone. Journal of Laboratory and Clinical Medicine 1983102 444-449.

57 Lippi G, Franchini M, Targher G, Montagnana M, Salvagno GL, Guidi GC \& Favaloro EJ. Hyperthyroidism is associated with shortened APTT and increased fibrinogen values in a general population of unselected outpatients. Journal of Thrombosis and Thrombolysis 200928 362-365.

58 Erem C. Blood coagulation, fibrinolytic activity and lipid profile in subclinical thyroid disease: subclinical hyperthyroidism increases plasma factor X activity. Clinical Endocrinology $2006 \mathbf{6 4}$ 323-329.

59 Morishita E, Hashimoto T, Asakura H, Saito M, Yamazaki M, Aoshima K, Yoshida T, Kato H \& Matsuda T. Increased plasma levels of free tissue factor pathway inhibitor in patients with Graves' disease. Thrombosis and Haemostasis 199879 919-923.

60 Chadarevian R, Bruckert E, Giral P \& Turpin G. Relationship between thyroid hormones and fibrinogen levels. Blood Coagulation \& Fibrinolysis 199910 481-486.

61 Diez JJ \& Iglesias P. Pulmonary thromboembolism after inferior petrosal sinus sampling in Cushing's syndrome. Clinical Endocrinology 199746 775-777.

62 Obuobie K, Davies JS, Ogunko A \& Scanlon MF. Venous thromboembolism following inferior petrosal sinus sampling in Cushing's disease. Journal of Endocrinological Investigation 2000 23 542-544.

63 La Brocca A, Terzolo M, Pia A, Paccotti P, De Giuli P \& Angeli A. Recurrent thromboembolism as a hallmark of Cushing's syndrome. Journal of Endocrinological Investigation 199720 211-214.

64 Small M, Lowe GD, Forbes CD \& Thomson JA. Thromboembolic complications in Cushing's syndrome. Clinical Endocrinology 198319 503-511.

65 Yoshimura S, Ago T, Kitazono T, Yonekura T, Kumai Y, Kuroda J, Kamouchi M, Ooboshi H, Ibayashi S \& Iida M. Cerebral sinus thrombosis in a patient with Cushing's syndrome. Journal of Neurology, Neurosurgery, and Psychiatry 200576 1182-1183.

66 Sjoberg HE, Blombäck M \& Granberg PO. Thromboembolic complications, heparin treatment in increase in coagulation factors in Cushing's syndrome. Acta Medica Scandinavica 1976 199 95-98.

67 Mancini T, Kola B, Mantero F, Boscaro M \& Arnaldi G. High cardiovascular risk in patients with Cushing's syndrome according to $1999 \mathrm{WHO} / \mathrm{ISH}$ guidelines. Clinical Endocrinology $200461768-777$.

68 Etxabe J \& Vazquez JA. Morbidity and mortality in Cushing's disease: an epidemiological approach. Clinical Endocrinology $199440479-484$.

69 Oikarinen A, Hoythya M \& Jarvinen M. Dexamethasoneinduced plasminogen activator inhibitor: characterization, purification and preparation of monoclonal anti-bodies. Archives of Dermatological Research 1990282 153-158.

70 Laug WE. Glucocorticoids inhibit plasminogen activator production by endothelial cells. Thrombosis and Haemostasis $1983 \mathbf{5 0} 888-892$.

71 Barouski-Miller A \& Gelehrter TD. Paradoxical effects of glucocorticoids on regulation of plasminogen activator activity of rat hepatoma cells. PNAS 198279 2319-2322.

72 Jacoby R, Owings J, Ortega T, Gosselin R \& Feldman E. Biochemical basis for the hypercoagulable state seen in Cushing syndrome. Archives of Surgery 2001136 1003-1007.

73 Fatti LM, Bottasso B, Invitti C, Coppola R, Invitti F \& Mannucci PM. Markers of activation of coagulation and fibrinolysis in patients with Cushing's syndrome. Journal of Endocrinological Investigation 200023 145-150. 
74 Patrassi GM, Sartori MT, Viero ML, Scarano L, Boscaro M \& Girolami A. The fibrinolytic potential in patients with Cushing's disease: a clue to their hypercoagulable state. Blood Coagulation $\mathcal{E}$ Fibrinolysis 19923 789-793.

75 Kastelan D, Dusek T, Kraljevic I, Polasek O, Giljevic Z, Solak M, Salek SZ, Jelcic J, Aganovic I \& Korsic M. Hypercoagulability in Cushing's syndrome: the role of specific haemostatic and fibrinolytic markers. Endocrine 200936 70-74.

76 Erem C, Nuhoglu I, Yilmaz M, Kocak M, Demirel A, Ucuncu O \& Onder Ersoz H. Blood coagulation and fibrinolysis in patients with Cushing's syndrome: increased plasminogen activator inhibitor-1, decreased tissue factor pathway inhibitor, and unchanged thrombin-activatable fibrinolysis inhibitor levels. Journal of Endocrinological Investigation 200932 169-174.

77 Casonato A, Pontara E, Boscaro M, Sonino N, Sartorello F, Ferasin S \& Girolami A. Abnormalities of von Willebrand factor are also part of the prothrombotic state of Cushing's syndrome. Blood Coagulation \& Fibrinolysis 199910 145-151.

78 Patrassi GM, Dal Bo Zanon R, Boscaro M, Martinelli S \& Girolami A. Further studies on the hypercoagulable state of patients with Cushing's syndrome. Thrombosis and Haemostasis $1985 \mathbf{5 4} 518-520$.

79 Ambrosi B, Sartorio A, Pizzocaro A, Passini E, Bottasso B \& Federici A. Evaluation of haemostatic and fibrinolytic markers in patients with Cushing's syndrome and in patients with adrenal incidentaloma. Experimental and Clinical Endocrinology $\mathcal{E}$ Diabetes 2000108 294-298.

80 Boscaro M, Sonino N, Scarda A, Barzon L, Fallo F, Sartori MT, Patrassi GM \& Girolami A. Anticoagulant prophylaxis markedly reduces thromboembolic complications in Cushing's syndrome. Journal of Clinical Endocrinology and Metabolism $2002 \mathbf{8 7}$ 3663-3666.

81 Brotman DJ, Girod JP, Posch A, Jani JT, Patel JV, Gupta M, Lip GY, Reddy S \& Kickler TS. Effects of short-term glucocorticoids on hemostatic factors in healthy volunteers. Thrombosis Research $2006118247-252$.

82 Van Zaane B, Nur E, Squizzato A, Dekkers OM, Twickler MT, Fliers E, Gerdes VE, Büller HR \& Brandjes DP. Hypercoagulable state in Cushing's syndrome: a systematic review. Journal of Clinical Endocrinology and Metabolism 200994 2743-2750.

83 Sacca L, Napoli R \& Cittadini A. Growth hormone, acromegaly, and heart failure: an intricate triangulation. Clinical Endocrinology $2003 \mathbf{5 9} 660-671$.

84 Wildbrett J, Hanefeld M, Fücker K, Pinzer T, Bergmann S, Siegert G \& Breidert M. Anomalies of lipoprotein pattern and fibrinolysis in acromegalic patients: relation to growth hormone levels and insulin-like growth factor I. Experimental and Clinical Endocrinology \& Diabetes $1997105331-335$.

85 Sartorio A, Cattaneo M, Bucciarelli P, Bottasso B, Porretti S, Epaminonda P, Faglia G \& Arosio M. Alterations of haemostatic and fibrinolytic markers in adult patients with growth hormone deficiency and with acromegaly. Experimental and Clinical Endocrinology \& Diabetes $2000 \mathbf{1 0 8} 486-492$.

86 Landin-Wilhelmsen K, Tengborn L, Wilhelmsen L \& Bengtsson BA. Elevated fibrinogen levels decrease following treatment of acromegaly. Clinical Endocrinology $1997 \mathbf{4 6} 69-74$.

87 Delaroudis SP, Efstathiadou ZA, Koukoulis GN, Kita MD, Farmakiotis D, Dara OG, Goulis DG, Makedou A, Makris P, Slavakis A \& Avramides AI. Amelioration of cardiovascular risk factors with partial biochemical control of acromegaly. Clinical Endocrinology 200869 279-284.

88 Rosen $\mathrm{T} \&$ Bengtsson BA. Premature mortality due to cardiovascular disease in hypopituitarism. Lancet 1990336 285-288.

89 Tomlinson JW, Holden N, Hills RK, Wheatley K, Clayton RN, Bates AS, Sheppard MC \& Stewart PM. Association between premature mortality and hypopituitarism. West Midlands Prospective Hypopituitary Study Group. Lancet 2001357 425-431.

90 Elhadd TA, Abdu TA \& Clayton R. Hypopituitarism and atherosclerosis. Annals of Medicine 200133 477-485.
91 Elhadd TA, Abdu TA, Oxtoby J, Kennedy G, McLaren M, Neary R, Belch JJ \& Clayton RN. Biochemical and biophysical markers of endothelial dysfunction in adults with hypopituitarism and severe GH deficiency. Journal of Clinical Endocrinology and Metabolism 200186 4223-4232.

92 Johansson JO, Landin K, Tengborn L, Rosén T \& Bengtsson BA. High fibrinogen and plasminogen activator inhibitor activity in growth hormone-deficient adults. Arteriosclerosis, Thrombosis, and Vascular Biology 199414 434-437.

93 Johansson JO, Landin K, Johannsson G, Tengborn L \& Bengtsson BA. Long-term treatment with growth hormone decreases plasminogen activator inhibitor-1 and tissue plasminogen activator in growth hormone-deficient adults. Thrombosis and Haemostasis $1996 \mathbf{7 6} 422-428$.

94 Kvasnicka J, Marek J, Kvasnicka T, Weiss V, Marková M, Stěpán J \& Umlaufová A. Increase of adhesion molecules, fibrinogen, type1 plasminogen activator inhibitor and orosomucoid in growth hormone $(\mathrm{GH})$ deficient adults and their modulation by recombinant human $\mathrm{GH}$ replacement. Clinical Endocrinology 200052 543-548.

95 Pfeifer M, Verhovec R, Zizek B, Prezelj J, Poredos P \& Clayton RN. Growth hormone $(\mathrm{GH})$ treatment reverses early atherosclerotic changes in GH-deficient adults. Journal of Clinical Endocrinology and Metabolism $1999 \mathbf{8 4} 453-457$.

96 Gomez JM, Sahún M, Vila R, Domènech P, Catalina P, Soler J \& Badimón L. Peripheral fibrinolytic markers, soluble adhesion molecules, inflammatory cytokines and endothelial function in hypopituitary adults with growth hormone deficiency. Clinical Endocrinology $2006 \mathbf{6 4} 632-639$.

97 Miljic D, Miljic P, Doknic M, Pekic S, Djurovic M, Colovic M \& Popovic V. Changes in prothrombin and activated partial thromboplastin time during replacement therapy with human recombinant growth hormone in growth hormone deficient adults. Hormones 20065 187-191.

98 Wallaschofski H, Kobsar A, Sokolova O, Eigenthaler M \& Lohmann T. Co-activation of platelets by prolactin or leptin pathophysiological findings and clinical implications. Hormone and Metabolic Research 200436 1-6.

99 Wallaschofski H, Donné M, Eigenthaler M, Hentschel B, Faber R, Stepan H, Koksch M \& Lohmann T. PRL as a novel potent cofactor for platelet aggregation. Journal of Clinical Endocrinology and Metabolism $2001865912-5919$.

100 Wallaschofski H, Kobsar A, Koksch M, Siegemund A, Hentschel B, Tuschy U, Lohmann T, Sokolova O \& Eigenthaler M. Prolactin receptor signaling during platelet activation. Hormone and Metabolic Research 200335 228-235.

101 Wallaschofski H, Lohmann T, Hild E, Kobsar A, Siegemund A, Spilcke-Liss E, Hentschel B, Stumpf C, Daniel WG, Garlichs CD \& Eigenthaler M. Enhanced platelet activation by prolactin in patients with ischemic stroke. Thrombosis and Haemostasis 2006 96 38-44.

102 Raaz D, Wallaschofski H, Stumpf C, Yilmaz A, Cicha I, Klinghammer L, Daniel WG, Lohmann T \& Garlichs CD. Increased prolactin in acute coronary syndromes as putative co-activator of ADP-stimulated P-selectin expression. Hormone and Metabolic Research 200638 767-772.

103 Norman RJ, Dewailly D, Legro RS \& Hickey TE. Polycystic ovary syndrome. Lancet $2007 \mathbf{3 7 0} 685-697$.

104 Meyer C, McGrath BP \& Teede HJ. Overweight women with polycystic ovary syndrome have evidence of subclinical cardiovascular disease. Journal of Clinical Endocrinology and Metabolism $2005905711-5716$.

105 Christian RC, Dumesic DA, Behrenbeck T, Oberg AL, Sheedy PF \& Fitzpatrick LA. Prevalence and predictors of coronary artery calcification in women with polycystic ovary syndrome. Journal of Clinical Endocrinology and Metabolism $2003 \mathbf{8 8} 2562$ 2568 .

106 Wild S, Pierpoint T, McKeigue P \& Jacobs H. Cardiovascular disease in women with polycystic ovary syndrome at long-term follow-up: a retrospective cohort study. Clinical Endocrinology 200052 595-600. 
107 Yildiz BO, Haznedaroglu IC, Kirazli S \& Bayraktar M. Global fibrinolytic capacity is decreased in polycystic ovary syndrome, suggesting a prothrombotic state. Journal of Clinical Endocrinology and Metabolism 200287 3871-3875.

108 Kelly CJ, Lyall H, Petrie JR, Gould GW, Connell JM, Rumley A, Lowe GD \& Sattar N. A specific elevation in tissue plasminogen activator antigen in women with polycystic ovary syndrome. Journal of Clinical Endocrinology and Metabolism 200287 3287-3290.

109 Atiomo WU, Bates SA, Condon JE, Shaw S, West JH \& Prentice AG. The plasminogen activator system in women with polycystic ovary syndrome. Fertility and Sterility $199869236-241$.

110 Erdoğan M, Karadeniz M, Alper GE, Tamsel S, Uluer H, Cağlayan $\mathrm{O}$, Saygili $\mathrm{F} \&$ Yilmaz C. Thrombin-activatable fibrinolysis inhibitor and cardiovascular risk factors in polycystic ovary syndrome. Experimental and Clinical Endocrinology $\mathcal{E}$ Diabetes $2008116143-147$.

111 Adali E, Yildizhan R, Kurdoglu M, Bugdayci G, Kolusari A \& Sahin HG. Increased plasma thrombin-activatable fibrinolysis inhibitor levels in young obese women with polycystic ovary syndrome. Fertility and Sterility 2009. In Press. DOI: 10.1016/ j.fertnstert.2009.03.037.

112 Orio F Jr, Palomba S, Cascella T, Tauchmanovà L, Nardo LG, Di Biase S, Labella D, Russo T, Savastano S, Tolino A, Zullo F, Colao A \& Lombardi G. Is plasminogen activator inhibitor-1 a cardiovascular risk factor in young women with polycystic ovary syndrome? Reproductive Biomedicine Online 20049 505-510.

113 Lind L, Jacobsson S, Palmér M, Lithell H, Wengle B \& Ljunghall S. Cardiovascular risk factors in primary hyperparathyroidism: a 15-year follow-up of operated and unoperated cases. Journal of Internal Medicine 1991230 29-35.

114 Lundgren E, Lind L, Palmér M, Jakobsson S, Ljunghall S \& Rastad J. Increased cardiovascular mortality and normalized serum calcium in patients with mild hypercalcemia followed up for 25 years. Surgery $2001130978-985$.

115 Hedbäck G \& Odén A. Persistent disease after surgery for primary hyperparathyroidism: the long-term outcome. European Journal of Endocrinology 2004150 19-25.

116 Erem C, Kocak M, Nuhoglu I, Yilmaz M \& Ucuncu O. Increased plasminogen activator inhibitor-1, decreased tissue factor pathway inhibitor, and unchanged thrombin-activatable fibrinolysis inhibitor levels in patients with primary hyperparathyroidism. European Journal of Endocrinology 2009160 863-868.

117 Erem C, Kocak M, Hacihasanoglu A, Yilamaz M, Saglam F \& Ersoz HO. Blood coagulation, fibrinolysis and lipid profile in patients with primary hyperparathyroidism: increased plasma factor VII and X activities and D-Dimer levels. Experimental and Clinical Endocrinology \& Diabetes 2008116 619-624.

118 Chertok-Shacham E, Ishay A, Lavi I \& Luboshitzky R. Biomarkers of hypercoagulability and inflammation in primary hyperparathyroidism. Medical Science Monitor 200814 628-632.

119 Cornier MA, Dabelea D, Hernandez TL, Lindstrom RC, Steig AJ, Stob NR, Van Pelt RE, Wang H \& Eckel RH. The metabolic syndrome. Endocrine Reviews 200829 777-822.

120 Franchini M, Targher G, Montagnana M \& Lippi G. The metabolic syndrome and the risk of arterial and venous thrombosis. Thrombosis Research 2008122 727-735.

121 Trost S, Pratley R \& Sobel B. Impaired fibrinolysis and risk for cardiovascular disease in the metabolic syndrome and type 2 diabetes. Current Diabetes Reports 20066 47-54.

122 Palomo I, Alarcon M, Moore-Carrasco R \& Argiles JM. Hemostasis alterations in metabolic syndrome. International Journal of Molecular Medicine 200618 969-974.

123 Mina A, Favaloro EJ \& Koutts J. Hemostatic dysfunction associated with endocrine disorders as a major risk factor and cause of human morbidity and mortality: a comprehensive meta-review. Seminars in Thrombosis and Hemostasis 200733 798-809.

124 Alessi MC \& Juhan-Vague I. Metabolic syndrome, haemostasis and thrombosis. Thrombosis and Haemostasis 200899 995-1000.
125 Després JP, Lemieux I, Bergeron J, Pibarot P, Mathieu P, Larose E, Rodés-Cabau J, Bertrand OF \& Poirier P. Abdominal obesity and the metabolic syndrome: contribution to global cardiometabolic risk. Arteriosclerosis, Thrombosis, and Vascular Biology 200828 1039-1049.

$126 \mathrm{Li} \mathrm{H} \mathrm{\&} \mathrm{Forstermann} \mathrm{U.} \mathrm{Nitric} \mathrm{oxide} \mathrm{in} \mathrm{the} \mathrm{pathogenesis} \mathrm{of}$ vascular disease. Journal of Pathology 2000190 244-254.

127 Bonetti PO, Lerman LO \& Lerman A. Endothelial dysfunction: a marker of atherosclerotic risk. Arteriosclerosis, Thrombosis, and Vascular Biology 200323 168-175.

128 Kim JA, Montagnani M, Koh KK \& Quon MJ. Reciprocal relationships between insulin resistance and endothelial dysfunction: molecular and pathophysiological mechanisms. Circulation 2006113 1888-1904.

129 Shoelson SE, Lee J \& Goldfine AB. Inflammation and insulin resistance. Journal of Clinical Investigation 2006116 1793-1801.

130 Van Gaal LF, Mertens IL \& De Block CE. Mechanisms linking obesity with cardiovascular disease. Nature $2006 \mathbf{4 4 4}$ 875-880.

131 Weisberg SP, McCann D, Desai M, Rosenbaum M, Leibel RL \& Ferrante AW. Obesity is associated with macrophage accumulation in adipose tissue. Journal of Clinical Investigation 2003112 1796-1808.

132 Nieuwdorp M, Stroes ES, Meijers JC \& Büller H. Hypercoagulability in the metabolic syndrome. Current Opinion in Pharmacology 20055 155-159.

133 Anfossi G, Russo I \& Trovati M. Platelet dysfunction in central obesity. Nutrition, Metabolism, and Cardiovascular Diseases 2009 $19440-419$.

134 Randriamboavonjy V \& Fleming I. Insulin, insulin resistance, and platelet signaling in diabetes. Diabetes Care 200932 528-530.

135 Olufadi R \& Byrne CD. Effects of VLDL and remnant particles on platelets. Pathophysiology of Haemostasis and Thrombosis 200635 281-291.

136 Fay WP, Garg N \& Sunkar M. Vascular functions of the plasminogen activation system. Arteriosclerosis, Thrombosis, and Vascular Biology 200727 1231-1237.

137 Diamant M, Nieuwland R, Pablo RF, Sturk A, Smit JW \& Radder JK. Elevated numbers of tissue-factor exposing microparticles correlate with components of the metabolic syndrome in uncomplicated type 2 diabetes mellitus. Circulation 2002106 2442-2447.

138 Targher G. Non-alcoholic fatty liver disease, the metabolic syndrome and the risk of cardiovascular disease: the plot thickens. Diabetic Medicine 200724 1-6.

139 Kotronen A \& Yki-Järvinen H. Fatty liver: a novel component of the metabolic syndrome. Arteriosclerosis, Thrombosis, and Vascular Biology 200828 27-38.

140 Targher G, Chonchol M, Miele L, Zoppini G, Pichiri I \& Muggeo M. Nonalcoholic fatty liver disease as a contributor to hypercoagulation and thrombophilia in the metabolic syndrome. Seminars in Thrombosis and Hemostasis 200935 277-287.

141 Targher G, Bertolini L, Rodella S, Lippi G, Franchini M, Zoppini G, Muggeo M \& Day CP. NASH predicts plasma inflammatory biomarkers independently of visceral fat in men. Obesity 200816 1394-1399.

142 Aubert H, Frere C, Aillaud MF, Morange PE, Juhan-Vague I \& Alessi MC. Weak and non-independent association between plasma TAFI antigen levels and the insulin resistance syndrome. Journal of Thrombosis and Haemostasis 20031 791-797.

143 Kopp CW, Kopp HP, Steiner S, Kriwanek S, Krzyzanowska K, Bartok A, Roka R, Minar E \& Schernthaner G. Weight loss reduces tissue factor in morbidly obese patients. Obesity Research 200311 950-956.

144 Mills JD, Mansfield MW \& Grant PJ. Factor XIII-circulating levels and the Val34Leu polymorphism in the healthy male relatives of patients with severe coronary artery disease. Thrombosis and Haemostasis $200287409-414$. 
145 Targher G, Bonadonna RC, Alberiche M, Zenere MB, Muggeo M \& Bonora E. Relationship between soluble adhesion molecules and insulin sensitivity in type 2 diabetic individuals. Role of adipose tissue. Diabetes Care 200124 1961-1966.

146 Arteaga RB, Chirinos JA, Soriano AO, Jy W, Horstman L, Jimenez JJ, Mendez A, Ferreira A, de Marchena E \& Ahn YS. Endothelial microparticles and platelet and leukocyte activation in patients with the metabolic syndrome. American Journal of Cardiology 200698 70-74.

147 Morange PE, Renucci JF, Charles MA, Aillaud MF, Giraud F, Grimaux M \& Juhan-Vague I. Plasma levels of free and total TFPI, relationship with cardiovascular risk factors and endothelial cell markers. Thrombosis and Haemostasis 200185 999-1003.

148 Klein I \& Ojamaa K. Thyroid hormone and the cardiovascular system. New England Journal of Medicine 2001344 501-509.
149 Hennekens CH, Dyken ML \& Fuster V. Aspirin as a therapeutic agent in cardiovascular disease: a statement for healthcare professionals from the American Heart Association. Circulation $1997962751-2753$.

150 Grundy SM, Cleeman JI, Daniels SR, Donato KA, Eckel RH, Franklin BA, Gordon DJ, Krauss RM, Savage PJ, Smith SC Jr, Spertus JA, Costa F, American Heart Association \& National Heart, Lung, and Blood Institute. Diagnosis and management of the metabolic syndrome: an American Heart Association/ National Heart, Lung, and Blood Institute Scientific Statement. Circulation 2005112 2735-2752.

Received 3 November 2009

Accepted 23 November 2009 